\title{
Gazete Haberlerinde Terör Saldırıları: Cumhuriyet Gazetesi 1930-2009 Örneklemi
}

DOI: $10.26466 /$ opus.639941

\section{Ceren Özbaşaran Tan ${ }^{*}$ - Neylan Ziyalar* - Faruk Aşıcıoğlu***}

* Dokt. Öğr, İstanbul Üniversitesi - Cerrahpaşa, Adli Tıp ve Adli Bilimler Ens./ İstanbul / Türkiye E-Posta: cerenozbasaran@hotmail.com

ORCID: 0000-0002-2468-588X

** Doç. Dr. İstanbul Üniversitesi - Cerrahpaşa / Adli Tip ve Adli Bilimler Ens. İstanbul / Türkiye E-Posta: neylan@istanbul.edu.tr

ORCID: 0000-0001-9626-3734

*** Prof. Dr., İstanbul Üniversitesi - Cerrahpaşa / Adli Tıp ve Adli Bilimler Ens.İstanbul / Türkiye

E-Posta: faruk.asicioglu@istanbul.edu.tr

ORCID: 0000-0003-1691-6171

\section{Öz}

Bu çalışmada; Cumhuriyet Gazetesi'nin basılı versiyonlarında yer almış, 1930 ve 2009 seneleri arasında Türkiye Cumhuriyeti Devleti'nin sınırları içerisinde gerçekleşen terör saldırıları incelenmiş ve bu terör saldırılarının fail, mağdur, tür, yer gibi ortak noktaları saptanarak bir çok profil çıkartılmıştır. Daha sonra bu ortak noktalara sahip profiller; kendi içlerinde anlamlı olacak şekilde kodlanmış ve daha sonra bu belirlenen kodların bir araya getirilmesi sonucu kategoriler yapılmıştır. Bulguların istatistiksel analizleri için IBM SPSS 21.00 (Sosyal Bilimler için İstatistik Paket Programı) istatistik programı kullanılmıştır. Elde edilen veriler değerlendirilirken; Yüzde, Frekans, (Aritmetik) Ortalama ve Standart sapma gibi betimsel istatistikler ile çalışılmıştır. İçerik analizi yöntemi kullanılarak yapılan çalışma sonucunda; 43 tanesi manşetten verilmiş olmak üzere toplam 156 terör haberine ulaşılmıştır. Manşet haberlerinin ilki 1979 senesinde, manşet dışı verilen haberlerin ilki ise 1977 senesinde gazetede yer almıştır. Faaliyet gösterdiği belirlenen 22 terör örgütü / terörist grup saptanmıştır. Haberlerin \%61.08'inde herhangi bir görsel kullanılmamış ve söylem açısından (doğrudan eylemi açıklayıcl, vahşet, infial yaratan, hedef gösteren gibi...) farklılıklar saptanmıştır.

Anahtar Kelimeler: Cumhuriyet Gazetesi, terör, saldırı, içerik analizi 


\title{
Terrorist Attacks in Newspaper Reports: Cumhuriyet Newspaper 1930-2009 Sample
}

\begin{abstract}
In this study; the terorist attacks occured in the Republic of Turkey between 1930-2009 are examined and the comman points were determined and the common points of these terrorist attacks such as perpetrators, victims, species, and places were determined and many profiles were created. Then the profiles with these common points are encoded so that they are meaningful in themselves, and the categories are made as a result of codes. For statistical analysis of the findings, the IBM SPSS 21.00 (statistical package program for the Social Sciences) statistical program was used. Descriptive statistics such as percentage, frequency, mean and standard deviation were used when evaluating the data.As a result of the study, which was conducted using content analysis method, a total of 156 terror reports were reached, 43 of them from headlines. The first headline news appeared in the newspaper in 1979, and the first one out of headline news appeared in the newspaper in 1977. 22 terrorist organizations / terrorist groups determined to be operating were identified. In $61.08 \%$ of the news, no visual was used and differences in terms of discourse (such as direct explanatory action, brutality, indignation, targeting...) are determined.
\end{abstract}

Keywords: Cumhuriyet Newspaper, terror, attack, content analysis 


\section{Giriş}

Terör kelimesi, Latince "korku ve dehşet" anlamındaki "terrere" kelimesinden türemiştir. "Terör" kelimesini politik bağlamda ilk kullananlar Asurlular olmuştur (Fine, 2010). İnsanlık tarihi kadar eski bir kavram olan "terrörizm" kavramının temelleri; araştırmacılar tarafından, Sicarilerin M.S. 66-73 yılları arasında Romalılara karşı olan mücadelelerine kadar götürülmektedir (Dedeoğlu, 2003). Bununla birlikte; terör olgusunun sistematik bir şekilde kullanılmasının 13. Yüzyılın başlarında ortaya çıtığı ve Hasan Sabbah liderliğinde hareket eden Haşhaşiler ile olduğu belirtilmektedir (Akgün, 2006).

Modern anlamda ise terör; 1789 'daki Fransız Devrimi ile literatüre dâhil olmuştur (Eisenstein, 1991). Devrim liderlerinden, hukukçu ve politikacı Maxmilien François Marie Isidore de Robespierre'in, karşı devrimciler tarafından çıkarılan çeşitli ayaklanmaları bastırıp, mevcut kamusal düzeni korumak için yaptı̆̆ı ve yapılmasını önerdiği her türlü faaliyet "terör" olarak adlandırılmıştır (Gueniffey, 2013). Bahsi geçen dönemde "terör" sözcüğü şiddet olgusunu ifade ediyor olsa da; kamu düzeninin korunması adına kullanıldığı için aslında "olumlu" anlam barındırdığı düşünülmektedir (Marion 1993; Hoffman, 2003). "Terör" kelimesinin kavramsal açklamasında ilk kez la Dictionarire de I'Academic Francaise'nin 1789 senesindeki bir ek bask1sinda rastlanmaktadır (Laqueur, 1987).

Devrim dönemindeki kullanımından sonra; terör kelimesi "yönetim ve gücün kötüye kullanılması" anlamına evrilmiştir. 'Terörist' kelimesi ise, devrim boyunca olan tüm şiddet içeren hareketleri "küçümsemek" amacı ile ilk defa Edmund Burke tarafindan kullanılmıştır (Hoffman, 1998). Devrim sonrasında ise, genel olarak anarşistlerin hükümetlere karşı başkaldırı hareketleri "terör" olarak adlandırılmaya başlamıştır (Andress, 2008; Hoffman, 1998).

1900'lü senelerde terör terimi; işçi örgütlerinin haklarını korumak sebebiyle yaptıkları toplanma ve/veya eylemleri tanımlamak için kullanılmaya başlanmıştır (Hoffman, 2003). Lakin "terörizm" olgusu ve kelimesi, 2. Dünya Savaşı'ndan sonra tüm dünya ülkelerinde daha yaygın şekilde kullanılmaya başlanmıştır (Çağlar, 2018). 1950'li senelere gelindiğinde ise; terör terimi, milliyetçi ve ulusalcı grupların kendi memleketlerindeki çeşitli gruplara karşı davranışlarına verilen isim olarak karşımıza çıkmaktadır (Gerbner, 1993). 
Ülkemizde ise terör ve terörizm, 3713 sayılı Terörle Mücadele Kanunu'nun 1 . Maddesine göre;

"Terör, baskı, cebir ve şiddet, korkutma, yıldırma, sindirme veya tehdit yöntemlerinden biri ile Anayasada belirtilen Cumhuriyetin niteliklerini, siyasi, hukuki, sosyal, laik, ekonomik düzeni değiştirmek, Devletin ülkesi ve milleti ile bölünmez bütünlüğ̈̈nü bozmak, Türk Devletinin varllğın tehlikeye düşürmek, Devletin otoritesini zaafa uğratmak veya yıkmak veya ele geçirmek, temel hak ve hürriyetleri yok etmek, devletin iç ve dış güvenliğini, kamu düzenini veya genel sağhlğı bozmak amacryla bir örgüte mensup kişi veya kişiler tarafindan girişilecek her tür eylemlerdir"

şeklinde tanımlanmıştır (Terörle Mücadele Kanunu, 2013).

Terör ve terörizm aynı kavramlar olarak kullanılmakla beraber, alında görüldüğü üzere başka kavramları ifade etmektedir. Terör, korku durumunu; terörizm ise, hedeflenen korkunun oluşumunu amaçlayan bir stratejiyi veya stratejik hamleyi ifade etmektedir (TBB, 2006). Terör ve terörizm kavramları arasındaki en mühim farklılık; terörün, herhangi bir iradee ihtiyaç duyulmadan da aniden oluşabilen, anlık, genellikle sistemsiz bir şiddet olgusunu ifade ediyor olmasıdır. Terörizmin ise terörün; sistematik, iradi, çoğu kez örgütlü ve uzun süreli kullanımını içeren bir kuralsız savaş ve propaganda tekniğidir (Ayhan, 2015).

Bilindiği üzere, düşünce ancak hareket niteliği kazandığında halinde suç teşkil etmektedir. Bunun için başka bir kişiye veya olguya maddi ve/veya manevi zarar veren bir eylemin (Örneğin silahlı saldırı, bomba, propaganda, vb.) olmasi gerekmektedir (TBB, 2006; Andress, 2008). Lakin herhangi bir eylem olmaksızın, tek başına bile bu kelime artık insanlarda oldukça rahatsız edici bir etki bırakabilmektedir.. (Ayhan, 2015).

Terörizmin vücut bulmuş hali olan terör saldırılar; hem meydana geldiği ülke, hem de dünyanın geneli açısından bakıldığında, propaganda hareketleri olarak nitelendirilebilirler (Gabort, 1987). Bu saldırılar simgesel anlamlar taşıdıkları için; teröristler ve / veya terör grupları, hızlı ve etkin biçimde izlenme, dinlenme veya okunma yoluyla kolaylıkla eylemlerini duyurma imkânına sahip olmaktadırlar (Gerbner, 1993; Wilkinson, 1997). Terörizmin medyayı kullanarak elde etmek istediği en büyük amaç, örgütün tanıtımını yapmaktır. Dolayısıyla medyanın üzerine birçok konuda olduğu gibi terör konusunda da önemli görevler düşmektedir (Alali, 1994). Medyanın, toplumun huzur ve barışını tehdit eden sorunların çözümlenmesinde ve dengede 
tutulmasında hassas davranması, haberlerinde özenli bir dil kullanması ve terörün amacına hizmet edebilecek her türlü yayından kaçınması gerekliliği bu görevlere örnek verilebilir (Şeker, 2009).

Çalışmanın temel amac1; kamuoyunu haberdar etme görevi olan gazeteler içerisinden kaynak olarak belirlenmiş bir ulusal gazetenin; Türkiye Cumhuriyeti sınırları içerisinde gerçekleşen terör saldırılarına dair haberleri sözel ve görsel bakımdan sınıflandırmak üzere içerik analizinin gerçekleştirilmesidir. Söz konusu gazete haberlerindeki terör saldırılarına yönelik kullanılan sözel/görsel içeriklerin yanı sıra; ülkemiz sınırları içerisinde hangi terör grupları ve/veya örgütlerinin eylem gerçekleştirdikleri, bu eylemlerin hedef kitleleri, gerçekleştirildikleri yer ve saldırıların türleri ve oluşan değişimler de ortaya koyulmaktadır.

\section{Gereç ve Yöntem}

Çalışmada, Türkiye Cumhuriyeti sınırları içerisindeki bireylere (sivil vatandaş, askeri veya kolluk personeli, turist, göçmen vb.) yönelik faaliyet göstermekte olan bölgesel veya küresel nitelikli örgütlerin gerçekleştirmiş olduğu saldırılara dair gazete haberleri taranmıştır. Cumhuriyet Gazetesi çalışmanın temel kaynağı olarak belirlenmiştir. Cumhuriyet Gazetesi 1924 yılında Yunus Nadi tarafından kurulmuş ve günümüzde yayım hayatına devam etmekte olan köklü ve eski bir gazetedir. Söz konusu gazetenin seçiminde, gazetenin tirajı ve/veya ideolojik yönelimi dikkate alınmaksızın; diğer ulusal gazetelerden çok daha eski bir tarihte yayım hayatına başlamış olması ve elektronik arşiv erişilebilirliği açısından en uygun kaynak olması etkili olmuştur.

Kaynak olarak belirlenmiş olan Cumhuriyet Gazetesinin yalnızca basılı versiyonunun terör saldırısını izleyen güne ait ilk (birinci) sayfası çalışma kapsamına alınmıştır. Gazeteye ait elektronik arşivde erişilebilen en eski tarih 1 Ocak 1930 olmuştur. Belirlenen tarihten 1 Ocak 2010 tarihine dek olan 80 senelik süreç için, "terör eylemi" veya "terör saldırısı" olarak nitelendirilebilecek her türlü olaya ait habere ulaşılmıştır. 1 Ocak 2010 ve 1 Ocak 2019 arasındaki dönem ise "Gazete Haberlerinde Terör Saldırıları: Cumhuriyet Gazetesi 2010-2019 Örneklemi" isimli bir diğer çalışmada incelenmiştir.

Cumhuriyet Gazetesi Elektronik Arşivi bünyesindeki "Gelişmiş Arama" seçeneği ile ulaşılmak istenen nitelikteki haberlere yönelik bir tarama gerçek- 
leştirilmiştir. Bu doğrultuda, herhangi bir saldırıya ait haberin kesinlikle içermesi gereken anahtar kelime olarak "terör" kelimesi belirlenmiştir. Bunun yanı sıra; haber içeriğinde veya başlığında geçmesi çalışma için gerekli olan haberlere ulaşımı kolaylaştıracağı ve zaman tasarrufu sağlayacağı için haber metninde veya başlıkta bulunması gereken diğer alternatif kelimeler de (saldırı / patlama) aramaya dâhil edilmiştir.

Araştırmadan elde edilen bilgiler incelenerek, kavramlara ilişkin ortak noktalar saptanmıştır. Daha sonra bu ortak noktalar kendi içlerinde anlamlı olacak şekilde kodlanmış ve kodların bir araya getirilmesi sonucu kategoriler oluşturulmuştur.

Araştırma kodlaması, aşağıda belirtilmiş kavramsal tanımların açıklamalarına dayanarak oluşturulmuştur:

1. Olay tarihi: Terör olayının gazetede yer alış tarihi.

2. Haber başlı̆̆ı söylemi: Gazetenin ilk sayfasında terör haberinin hangi başlıkla verildiği ve bu başlı̆̆ın söylem niteliği (Doğrudan eylemi açıklayıcl, vahşet söylemi, infial, hedef gösteren, tepkisel)

3. Başlık konumu: Haberin gazetenin ilk sayfasının neresinde yer aldığı. (Manşet, diğger)

4. Olay türü: Terör olayını gerçekleştirme türü (Silahlı saldırı, bomba, taş, roketatar, mayin, molotof.)

5. Hedef: Terör olayının hedefi olarak gösterilen kitle (Sivil, polis, asker, öğretmen, kamu görevlisi, iş̧̧, milletvekili, konsolosluk görevlisi.)

6. Mekân: Terör olayının gerçekleştiği yer (Toplu taşıma, Cafe / Restaurant, eczane / hastane, otel, üniversite / okul, sokak, banka, is yeri, hastane, ev, cami, dernek / vakuf, market / avm, karakol, araç, servis, lojman, vb.)

7. Fail: Terör olayını gerçekleştirdiği söylenen / şüphelenilen / üstlenen kişi, grup veya örgüt (Bkz. Tablo 1.)

8. Görsel sayısı: Haberde yer verilen görsellerin sayısı.

9. Görsel içeriği: Haberde yer verilen görsellerin içeriği (Şahıs, olay yeri, harita, kroki, diğer)

Elde edilen gazete haberleri; içerik analizi yöntemi kullanılarak incelenmiştir. İçerik analizi yöntemi yetkin bir biçimde ilk olarak Berelson'un çalışmalarında ele alınmıştır (Berelson, 1948). 1952 senesinde yayınlanan 'Content Analysis in Communication Research' isimli kitap; içerik analizi yöntemiyle yapılacak çalışmalara ilişkin kuramsal bir çerçeve sunan ilk sistematik yayın olarak kabul edilmektedir (Krippendorff, 2004; 2013). 
Yazılı, görsel, işitsel ve/veya her türlü kayıtlı materyale uygulanabilen içerik analizi; geniş ölçekli çalışmalar içinde, kavram ve temaların incelenmesi, materyal sağlamadaki kolaylığı, geniş verileri kolay işlenebilen sayısal verilere dökebilmesi gibi açlardan araştırmacılara avantaj sağlayan bir yöntemdir (Berger, 1998; Pooley 2008). Televizyon, gazete ve/veya diğer kitle iletişim araçları kullanılarak yapılan araştırmalarında nicel, objektif ve sistematik bir çalışma olanağı sağlar (Geray, 2014).

Bulguların istatistiksel analizleri için IBM SPSS 21.00 (Sosyal Bilimler için İstatistik Paket Programı) istatistik programındaki Yüzde, Frekans, (Aritmetik) Ortalama ve Standart sapma gibi betimsel istatistikler kullanılmıştır.

\section{Bulgular}

1 Ocak 1930 - Ocak 2010 tarihleri arasında; daha önce belirlenen arama kriterleri ile yapılan aramalar sonucunda; "terör saldırısı" olarak nitelendirilebilecek toplam 156 olay saptanmıştır. Bu olaylar haberleştirilirken; 43 tanesi manşetten, diğerleri ise ilk sayfanın herhangi başka bir yerinde yer almıştır. 156 olayın toplam 22 faili bulunmaktadır.

Tablo 1. Terör Örgütleri ve Terörist Gruplar (Failler)

\begin{tabular}{llll}
\hline 0. & Belirsiz & 1. & İslami Direniş Örgütü \\
\hline 2. & Komandolar & 3. & KABT $^{*}$ \\
\hline 4. & Ülkücüler & 5. & PKK $^{*}$ \\
\hline 6. & Sağcı Terör Örgütü & 7. & ARGK $^{*}$ \\
\hline 8. & Anti Terör Birliği & 9. & İslami Hareket \\
\hline 10. & TKP/ML - TíKKO* & 11. & DEV-SOL \\
\hline 12. & Faşistler & 13. & İslam Cihad \\
\hline 14. & Anarşistler & 15. & IBDA-C \\
\hline 16. & Ayrilıç Teröristler & 17. & Yekgirtü \\
\hline 18. & Filistin İntikam Örgütü & 19. & DHKP/C \\
\hline 20. & El-Kaide & 21. & Hizbullah \\
\hline 22. & TAK & 23. & \\
\hline
\end{tabular}

*(TKP/ML -TIKKKO: Türkiye-Marksist-Leninist Komünist Partisi-Türkiye İşçi Köylü Kurtuluş Ordusu, KABT: Kuzey Arap Birliği Teşkilatı, PKK: Kürdistan İşçi Partisi, ARGK: Kürdistan Halk Kurtuluş Ordusu, IBDA-C: İslami büyük Doğu Akıncuları Cephesi, Yekgirtû: Kürdistan İslami birliği (Irak), DHKP/C : Devrimci Halk Kurtuluş Partisi Cephesi, TAK: Kürdistan Özgürlük Şahinleri

Tablo 1'e göre; 1 Ocak 1930 ile 1 Ocak 2010 tarihleri arasında Cumhuriyet Gazetesi'nin yalnızca basılı nüshasının ilk (birinci) sayfasında yer alan terör haberlerinin taranması sonucu, 22 terör örgütü ve/veya terör grubu tespit 
edilmiş ve her biri özel numaralar ile kodlanmıştır. Gazete haberinde herhangi bir grup veya örgüte atıf yapılmayan haberler için ise "belirsiz" kodu kullanılmıştır. 1'den 22'ye kadar kodlanan terör örgütlerinin ve terörist grupların isimleri; gazetede yer aldığı şekiller korunarak çalışmamıza aktarılmış ve herhangi bir kısaltma veya yorum kullanılmamıştır.

Failler; Komandolar, Ülkücüler, Sağcc Terör Örgütleri, Anti Terör Birliği, TKP/ML - TíKKO, Faşistler, Anarşistler, Ayrılıkçı Teröristler, Filistin İntikam Örgütü, İslami Direniş Örgütü, KABT, PKK, ARGK, İslami Hareket, DEVSOL, İslam Cihad, IBDA-C, Yekgirtû, DHKP/C, Hizbullah, El-Kaide ve TAK isimleriyle gazetede yer almışlardır. Komandolar, ülkücüler, sağcı terör örgütleri ve faşistler sağ görüşlü; PKK, ARGK, Yekgirtû ve TAK Kürt hareketine bağll; Anti-Terör Birliği, Anarşistler, TKP/ML - TIKKO, DEV-SOL, $\mathrm{DHKP} / \mathrm{C}$ sol görüşlü, Filistin İntikam Örgütü, İslami Direniş Örgütü, KABT, İslami Hareket, İslam Cihad, IBDA-C, Hizbullah ve El-Kaide ise İslamc terör örgütleri olarak nitelendirilmektedir. Görüldüğü üzere; incelenen haberler kapsamında, en fazla faaliyet gösteren terör grupları ve/veya örgütleri İslamcı silahlı terör örgütler $(\mathrm{N}=8)$ olmuştur.

Tablo. 2 Haberler ve Görsel Sayısı

\begin{tabular}{lcccc}
\hline Haberin yeri & Haber sayıs & Görsel içeren haber & frekans & Görsel sayısı \\
\hline manşet & $43(\% 27,56)$ & 34 & $\% 79,06$ & 52 \\
diğer & $113(\% 72,43)$ & 24 & $\% 21,2$ & 33 \\
\hline Toplam & $156(\% 100)$ & 58 & $\% 37,17$ & 85 \\
\hline
\end{tabular}

Tablo 2'ye göre; toplam 156 terör haberi yayınlanmıştır. Bu haberlerin 43'ü manşetten verilmiştir. Manşetten verilen haberlerin 34 tanesinde görsel kullanılmıştır. Haberlerin 113'ü ise ilk sayfada manşet dışı olan bir yerden ( sürmanşet, sayfa eteği, vb....) verilmiştir. Bu haberlerin 24 tanesinde görsel kullanılmıştır. Kullanılan görsel sayısı; manşet haberlerinde 52, manşet dışı verilen haberlerde ise 33'tür.

Manşetten verilen haberlerde büyük ölçüde $(\% 79,06)$ görsel kullanımı yapılmıştır. Hemen hemen her manşet haberinde en az bir, en çok 4 görsel kullanılırken; olay yeri fotoğrafları ile olayın gerçekleştiği bölgenin haritası veya krokisi büyük ölçüde yer kaplamaktadır. Manşet dışı haberlerde ise, aksine tüm türden fotoğraflara ve/veya krokilere yer verilmiştir (\%21,2). Toplam 98 haberde hiç görsel kullanımı yoktur 
Tablo 3. Haberler ve Görsel İçerikleri

\begin{tabular}{lcccccc}
\hline $\begin{array}{l}\text { Görsel içeriği } \\
\text { (diğer) }\end{array}$ & $\mathbf{( N )}$ & frekans & $\begin{array}{c}\text { Görsel içeriği } \\
\text { (manşet) }\end{array}$ & $\mathbf{( N )}$ & frekans & toplam \\
\hline olay yeri & 11 & $\% 33,33$ & olay yeri & 16 & $\% 30,76$ & 27 \\
harita / kroki & 10 & $\% 30,03$ & harita / kroki & 15 & $\% 28,84$ & 25 \\
Diğer & 6 & $\% 18,18$ & Şahis & 11 & $\% 21,15$ & 17 \\
Şahis & 6 & $\% 18,18$ & Diğer & 10 & $\% 19,23$ & 16 \\
& $\mathbf{3 3}$ & $\mathbf{\% 1 0 0}$ & & $\mathbf{5 2}$ & $\mathbf{\% 1 0 0}$ & \\
\hline
\end{tabular}

Tablo 3'te; manşetten verilen haberlerdeki 52 görselde ve manşet dışı yerden verilen haberlerdeki 33 görselde farklı frekanslarda içerikler kullanıldığı görülmektedir. Manşet ve manşet dışı verilen haberlerde en fazla olay yeri fotoğrafları (patlama gerçekleşen sokak, yanmış araba, ceset, vb.) ve harita / krokiler (saldırının gerçekleştiği bölgenin haritası, vb.) kullanılmıştır.

Tablo 4. Manşet Haberleri ve Söylem Türleri

\begin{tabular}{|c|c|c|}
\hline Söylem (manşet) & $(\mathrm{N})$ & frekans \\
\hline Doğrudan eylemi açıklayıcı & 12 & $\% 27,9$ \\
\hline Vahşet & 9 & $\% 20,93$ \\
\hline İnfial yaratan & 16 & $\% 37,20$ \\
\hline Hedef gösteren & 1 & $\% 2,32$ \\
\hline Tepkisel & 5 & $\% 11,62$ \\
\hline & 43 & $\% 100$ \\
\hline
\end{tabular}

Manşet haberlerinin \%37,20'sinde infial yaratan ("terör kol geziyor", "terör durmak bilmiyor", "cami bastılar", vb.), \%27,9'unda doğrudan eylemi açılayıcı ("İstanbul'da dün de bir öğrenci öldürüldü", "Zile'de olaylar: 1 ölü 12 yaralı", "Mardin'de çatışma ve 7 şehit" vb.), \%20,93'ünde vahşet ("vahşet: 16'sı çocuk 30 ölü", "PKK 13 çocuğu kurşuna dizdi", "PKK vahşeti” vb.), \%11,62'sinde tepkisel ("Terörü lanetliyoruz!", "Yıldıramazlar", "Canımız yandı!" vb.) , \%2,32'sinde ise hedef gösteren söylemlere yer verilmiştir (Tablo 4.)

Tablo 5. Diğer Haberler ve Söylem Türleri

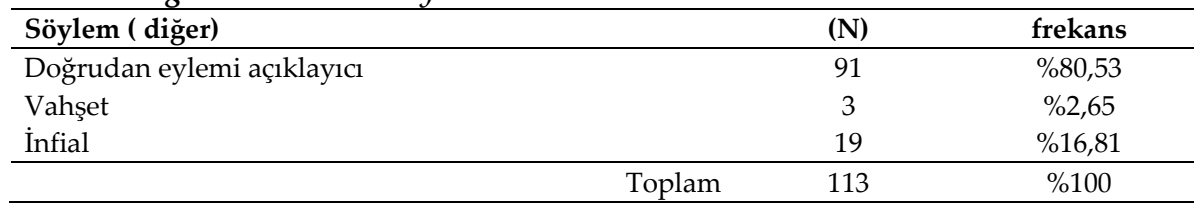


Tablo 5'te; gazete sayfasının manşet dışı bir yerinde yer alan haberlerin \%80,53'ünde doğrudan eylemi açıklayıc ("Doçent Cömert öldürüldü, eşi yaralandı", “CHP Ordu ilçe başkanının 5 yakını öldürdüler", "mayın tuzağı: 4 asker şehit" vb.) , \%16,81'inde infial yaratan ("PKK'den camide infaz", "PKK katliam yaptı: 12 ölü”, “Terörün önü alınamıyor: 4 ilde 10 kişi öldürüldü.." vb.), \%2,32'sinde vahşet söylemlerine ("PKK vahşeti”, "İstanbul'da kanlı pusu”, "Malatya'da çlgın terör" vb.) yer verilmiştir.

Söylem türleri açısından incelendiğinde ise; manşet haberlerinde en çok infial yaratan söylem, vahşet söylemi ve tepkisel söylemlere yer verildiği görülmektedir. Manşet dışı haberler; genelde daha net, anlaşılır ve doğrudan eylem açıklayıcı bir söylem tarzı benimsemektedir.

Tablo 6. Manşet Haberleri ve Hedef - Mekân Analizi

\begin{tabular}{|c|c|c|c|c|}
\hline Hedef (Manşet) & Yer & Frekans(\%) & $(\mathrm{N})$ & Toplam \\
\hline \multirow[t]{7}{*}{1 Siviller } & Cafe / Restaurant & 10,71 & 3 & $28(\% 100)$ \\
\hline & sokak & 32,14 & 9 & \\
\hline & banka & 7,14 & 2 & \\
\hline & iş yeri & 17,85 & 5 & \\
\hline & $\mathrm{ev}$ & 25,92 & 7 & \\
\hline & dernek/vakıf & 3,57 & 1 & \\
\hline & market / avm & 3,57 & 1 & \\
\hline \multirow[t]{3}{*}{2 Polis } & karakol & 50 & 2 & $4(\% 100)$ \\
\hline & lojman & 25 & 1 & \\
\hline & ev & 25 & 1 & \\
\hline 3 Öğretmen & sokak & 100 & 1 & $1(\% 100)$ \\
\hline \multirow[t]{3}{*}{5 Kamu görevlisi } & banka & 40 & 2 & $5(\% 100)$ \\
\hline & adliye & 40 & 2 & \\
\hline & araba & 10 & 1 & \\
\hline \multirow[t]{6}{*}{6 Asker } & karakol / bölük & 38,88 & 7 & $18(\% 100)$ \\
\hline & araç & 38,88 & 7 & \\
\hline & ev & 5,55 & 1 & \\
\hline & istasyon / durak & 5,55 & 1 & \\
\hline & orman / arazi & 5,55 & 1 & \\
\hline & işyeri & 5,55 & 1 & \\
\hline 10 Gayrimüslimler & sinagog & 100 & 2 & $2(\% 100)$ \\
\hline \multirow[t]{2}{*}{11 Konsolosluk çalışanı } & konsolosluk binası & 100 & 2 & $2(\% 100)$ \\
\hline & & Toplam & 60 & \\
\hline
\end{tabular}

Manşette yer alan toplam 43 haber vardır. Tablo 6.'ya göre; 60 ayrı hedef belirlenmiştir. Dolayısıyla; bazı terör saldırılarında birden fazla hedef olduğunu söylemek mümkündür. 
Manşet haberleri incelendiğinde; en çok sivillerin ( $\mathrm{N}=28)$, daha sonra da askerlerin $(\mathrm{N}=18)$ hedef alındığı terör olaylarına yer verildiği görülmektedir. Siviller sırasıyla sokak, ev, iş yeri, cafe/restaurant, banka, dernek/vakıf ve market avmlerde hedef alınmıştır. Askerler; karakolda ve askeri araçlarda hedef alınırken, nadiren de olsa ev, otobüs durağı ve/veya iş yeri gibi yerlerde terör örgütlerinin hedefi olmuşlardır. Kamu görevlilerine $(\mathrm{N}=5)$ banka ve adliyede, polislere $(\mathrm{N}=4)$ ise karakol ve lojmanda saldırı gerçekleşmiştir. Sinagog saldırısında gayrimüslimler, konsolosluk saldırısında ise resmi görevdeki konsolosluk çalışanları hedef alınmıştır.

Tablo 7. Diğer Haberler ve Hedef - Yer Analizi

\begin{tabular}{|c|c|c|c|c|c|}
\hline & Hedef (Diğer) & Yer & Frekans(\%) & (N) & Toplam \\
\hline \multirow[t]{13}{*}{1} & Siviller & Toplu Taşıma & 18,03 & 11 & $61(\% 100)$ \\
\hline & & Cafe / Restaurant & 4,91 & 3 & \\
\hline & & eczane / hastane & 1,63 & 1 & \\
\hline & & otel & 1,63 & 1 & \\
\hline & & üniversite / okul & 3,27 & 2 & \\
\hline & & sokak & 37,7 & 23 & \\
\hline & & banka & 1,63 & 1 & \\
\hline & & iş yeri & 6,55 & 4 & \\
\hline & & hastane & 3,27 & 2 & \\
\hline & & ev & 13,11 & 8 & \\
\hline & & cami & 3,27 & 2 & \\
\hline & & dernek / vakıf & 3,27 & 2 & \\
\hline & & market / avm & 1,63 & 1 & \\
\hline \multirow[t]{5}{*}{2} & Polis & karakol & 20 & 3 & $15(\% 100)$ \\
\hline & & sokak & 26,66 & 4 & \\
\hline & & araç / servis & 26,66 & 4 & \\
\hline & & lojman & 6,66 & 1 & \\
\hline & & Cafe / Restaurant & 20 & 3 & \\
\hline 3 & Öğretmen & okul & 100 & 2 & $2(\% 100)$ \\
\hline \multirow[t]{2}{*}{4} & Öğrenci & okul & 66,66 & 2 & $3(\% 100)$ \\
\hline & & sokak & 33,33 & 1 & \\
\hline \multirow[t]{3}{*}{5} & kamu görevlisi & belediye & 25 & 1 & $4(\% 100)$ \\
\hline & & müdürlük & 20 & 2 & \\
\hline & & araba & 25 & 1 & \\
\hline \multirow[t]{6}{*}{6} & Asker & sokak & 7,84 & 4 & $51(\% 100)$ \\
\hline & & karakol / bölük & 35,29 & 18 & \\
\hline & & araç & 49,01 & 25 & \\
\hline & & lojman & 1,96 & 1 & \\
\hline & & ev & 1,96 & 1 & \\
\hline & & orman / arazi & 3,92 & 2 & \\
\hline \multirow[t]{3}{*}{8} & İşçi & lojman & 33,3 & 1 & $3(\% 100)$ \\
\hline & & orman / açık alan & 33,3 & 1 & \\
\hline & & iş yeri / iş alanı & 33,3 & 1 & \\
\hline \multirow[t]{2}{*}{9} & Siyasetçi & ev & 100 & 1 & \\
\hline & & & Toplam & 140 & $1(\% 100)$ \\
\hline
\end{tabular}


Manşet dışında yer alan toplam 113 haber vardır. Tablo 7.'ye göre; 140 ayrı hedef belirlenmiştir. Dolayısıyla; manşet haberlerinde olduğu gibi; bazı terör saldırılarında birden fazla hedef olduğunu söylemek mümkündür.

Manşet dışı terör haberleri incelendiğinde; sivil vatandaşların 61 defa, askerlerin 51 defa, polislerin ise 15 defa terör saldırılarının hedefinde olduğu saptanmıştır. Mekân analizi yapıldığında; manşet dışı yerde yer alan terör saldırısı haberlerinde siviller en çok sokakta, toplu taşımada ve evlerinde; askerler, askeri araçta, karakolda, bölükte ve sokakta; Polisler ise polis aracında terörün hedefi olmuştur.

Tablo 8. Manşet Haberlerinin Senelere göre Failleri

\begin{tabular}{|c|c|c|c|c|c|c|c|c|c|c|c|c|c|c|}
\hline & \multicolumn{13}{|c|}{ Senelere göre Failler (MANŞET) Failler* } & \multirow[t]{2}{*}{ Toplam } \\
\hline & 0 & 4 & 5 & 6 & 9 & 10 & 12 & 13 & 14 & 15 & 17 & 20 & 21 & \\
\hline $\begin{array}{l}\text { Seneler } \\
1979\end{array}$ & & 1 & & & & & & & & & & & & 1 \\
\hline 1980 & 1 & & & 1 & & & & & & & & & & 2 \\
\hline 1986 & & & & & 1 & 1 & & & & & & & & 2 \\
\hline 1987 & & & & & & & 3 & & & & & & & 3 \\
\hline 1988 & & & & & & & 1 & & & & & & & 1 \\
\hline 1990 & & & & & & & & & 1 & & & & & 1 \\
\hline 1991 & 1 & & & & & & 3 & & & 3 & & & & 7 \\
\hline 1992 & & & & & & & 1 & & & 2 & & & & 3 \\
\hline 1993 & & & & & & & 1 & & & & & & & 1 \\
\hline 1994 & & & & & & & 1 & & & & 1 & & & 2 \\
\hline 1995 & 1 & & & & & & & & & & 1 & & & 2 \\
\hline 1998 & & & & & & & 2 & & & & & & & 2 \\
\hline 1999 & & & 2 & & & & & & & & & & & 2 \\
\hline 2003 & 1 & & & & & & & & & & & & 1 & 2 \\
\hline 2006 & 1 & & & & & & & & & & & 1 & & 2 \\
\hline 2007 & 1 & & & & & & 3 & & & & & & & 4 \\
\hline 2008 & 1 & & & & & & 2 & & & & & & 1 & 4 \\
\hline 2009 & & & & & & & 1 & & & & & & & 1 \\
\hline Toplam & 7 & 1 & 2 & 1 & 1 & 1 & 18 & 1 & 1 & 5 & 2 & 1 & 2 & 43 \\
\hline Failler & 0 & 4 & 5 & 6 & 9 & 10 & 12 & 13 & 14 & 15 & 17 & 20 & 21 & \\
\hline
\end{tabular}

*Failler $(0,4,5,6,9,10,12,13,14,15,17,20,21)$ Tablo. 1'deki açıklamalara göre kodlanmıştır.

Tablo 8'e göre; manşetten verilen ilk terör olayı 1979 senesinde gerçekleşmiştir. PKK 18, DEV-SOL 5, TKP/ML - TIKKKO 2, IBDA-C 2, El Kaide 2, Anti Terör Birliği, Faşistler, Ayrılıkçı Terör, ARGK, İslami Hareket ve Hizbullah da 1'er terör olayıyla manşete haber olmuştur. 7 adet saldırının failleri belirsizdir. 
Tablo 9. Diğer Haberlerin Senelere göre Failleri Senelere göre Failler (diğer) Toplam Failler*

\begin{tabular}{|c|c|c|c|c|c|c|c|c|c|c|c|c|c|c|c|c|c|c|}
\hline Seneler & 0 & 1 & 2 & 3 & 5 & 6 & 7 & 8 & 12 & 15 & 16 & 17 & 18 & 19 & 20 & 21 & 22 & \\
\hline 1977 & & 1 & & 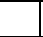 & & & & & & & & & & & & & & 1 \\
\hline 1978 & & 2 & 2 & 1 & & & & & & & & & & & & & & 5 \\
\hline 1980 & 5 & & 1 & & 1 & 6 & 1 & & & & & & & & & & & 14 \\
\hline 1984 & & & & & & & & 2 & & & & & & & & & & 2 \\
\hline 1987 & & & & & & & & & 3 & & & & & & & & & 3 \\
\hline 1989 & & & & & & & & & 1 & & & & & & & & & 1 \\
\hline 1990 & 1 & & & & 1 & & & & 2 & 1 & & & & & & & & 5 \\
\hline 1991 & 5 & & & & & & & & 7 & 1 & 1 & & & & & & & 14 \\
\hline 1992 & 2 & & & & & & & & 4 & & 1 & & & & & & & 7 \\
\hline 1993 & & & & & & & & & 2 & & & & & & & & & 2 \\
\hline 1994 & 1 & & & & & & & & & & & & & & & & & 1 \\
\hline 1995 & 1 & & & & & & & & 2 & & & & 1 & & & & & 4 \\
\hline 1996 & & & & & & & & & 1 & & & 1 & & & & & & 2 \\
\hline 1997 & & & & & & & & & 1 & & & & & & & & & 1 \\
\hline 1998 & & & & & & & & & 2 & & & & & 1 & & & & 3 \\
\hline 1999 & & & & & & & & & 1 & & & & & & & & & 1 \\
\hline 2000 & & & & & & & & & & & & & & & 1 & & & 1 \\
\hline 2003 & 1 & & & & & & & & & & & & & & & & & 1 \\
\hline 2004 & 2 & & & & & & & & & & & & & & & & & 2 \\
\hline 2005 & 1 & & & & & & & & 2 & & & & & & & 1 & & 4 \\
\hline 2006 & 5 & & & & 1 & & & & 5 & & & & & & 1 & & 1 & 13 \\
\hline 2007 & 4 & & & & & & & & 11 & & & & & & & & & 15 \\
\hline 2008 & 1 & & & & & & & & 5 & & & & & & & & & 6 \\
\hline 2009 & 1 & & & & & & & & 1 & & & & & & & & & 2 \\
\hline Toplam & 30 & 3 & 3 & 1 & 3 & 6 & 1 & 2 & 50 & 2 & 2 & 1 & 1 & 1 & 2 & 1 & 1 & 111 \\
\hline Failler & 0 & 1 & 2 & 3 & 5 & 6 & 7 & 8 & 12 & 15 & 16 & 17 & 18 & 19 & 20 & 21 & 22 & \\
\hline
\end{tabular}

${ }^{*}$ Failler $(0,1,2,3,5,6,7,8,12,15,16,17,18,19,20,21,22)$ Tablo. 1'deki açıklamalara göre kodlanmıştır.

Tablo 9.'a göre Gazetenin manşet dışı kısımlarında yer alan ilk terör haberi 1977 senesindedir. PKK 50, Faşistler 6, Komandolar 3, Ülkücüler 3, TKP/ML - TIKKO 3, Ayrılıkçı Terör 2, DEV-SOL 2, İslami Cihad 2, Hizbullah 2 terör olayıyla ilişkilendirilmiştir. 30 adet saldırının failleri belirsizdir.

Bu çalışmada haber analiz taraması 1 Ocak 1930'dan başlatılmış ise de; arama kriterlerine göre kaydedilen ilk terör olayı 22 Temmuz 1977 tarihinde "komandolar" adı verilen terörist grup tarafından gerçekleştirilmiştir ancak bu haber manşet dışı verilmiştir. 
Tablo 10. Failler ve Hedefleri

\begin{tabular}{|c|c|c|c|c|c|c|c|c|c|c|c|c|c|}
\hline & & $\begin{array}{l}\overrightarrow{\tilde{N}} \\
\tilde{\omega}\end{array}$ & $\frac{n}{0}$ & 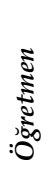 & 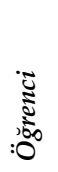 & $\underset{\mathbb{E}}{\mathbb{Z}}$ & $\frac{\bar{s}}{\frac{\pi}{2}}$ & 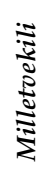 & 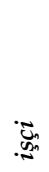 & 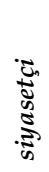 & 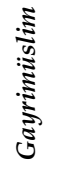 & 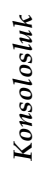 & \\
\hline 0. & Belirsiz & 19 & 7 & & 2 & 13 & & & 1 & & & & 42 \\
\hline 1. & Komando & 2 & 2 & & & & & & & & & & 4 \\
\hline 2. & Ülkücüler & 2 & 2 & & & & & & & & & & 6 \\
\hline 3. & Sağc1 terör örgütleri & 1 & & & & & & & & & & & 1 \\
\hline 4. & Anti terör birliği & 1 & & & & & & & & & & & 1 \\
\hline 5. & TKP/ML -TİKKO & 2 & 1 & 1 & 1 & 1 & & & & & & & 6 \\
\hline 6. & Faşistler & 6 & & & & 1 & 1 & 1 & & & 1 & & 10 \\
\hline 7. & Anarşist & & 1 & & 1 & & & & 1 & & & & 3 \\
\hline 8. & Ayrılıkçı terörist & & & & & & 2 & & & & & & 2 \\
\hline 9. & Filistin İntikam Örgütü & & & & & & & & & & 1 & & 1 \\
\hline 10. & İslami direniş & & & & & & & & & & 1 & & 1 \\
\hline 11. & KABT & & & & & & & & & & 1 & & 1 \\
\hline 12. & PKK & 19 & 6 & & & 1 & 46 & & 2 & & & & 74 \\
\hline 13. & ARGK & 1 & & & & & & & & & & & 1 \\
\hline 14. & İslami hareket & 1 & & & & & & & & & & & 1 \\
\hline 15. & DEV SOL & 1 & 3 & & & 1 & 2 & & & & & & 7 \\
\hline 16. & İslami cihad & 1 & & & & & 2 & & & & & & 3 \\
\hline 17. & IBDA-C & 3 & & & & & & & & & & & 3 \\
\hline 18. & Yekgirtû & 1 & & & & & & & & & & & 1 \\
\hline 19. & DHKP/C & & & & & & 1 & & & & & & 1 \\
\hline 20. & Hizbullah & 2 & & & & 1 & & & & & & & 3 \\
\hline 21. & El-Kaide & 1 & & & & & & & & & 1 & 1 & 3 \\
\hline \multirow[t]{2}{*}{22.} & TAK & & 1 & & & & & & & & & & 1 \\
\hline & Toplam & 63 & 21 & 3 & 4 & 7 & 67 & 1 & 3 & 1 & 5 & 1 & 176 \\
\hline
\end{tabular}

Tablo 10' da görüldüğü üzere; göre askerler 67 , siviller ise 63 defa terör saldırılarının hedefinde yer almışlardır. Polislere karşı 21, kamu görevlilerine karşı 7, gayrimüslimlere karşı 5, öğrencilere karşı 4, öğretmen ve işçilere karşı 3'er, milletvekilleri, siyasetçiler ve konsolosluk çalışanlarına karşı 1'er terör saldırısı olmuştur.

En fazla terör saldırısı PKK tarafından gerçekleştirilmiştir. PKK ilk saldırısın 10 Temmuz 1987'de gerçekleştirmiştir. Senelerin analizi yapıldığında; en çok saldırı 2007 senesinde ( $\mathrm{N}=14$ ) yapılmıştır. 
Tablo 11. Failler ve Saldırı Türleri

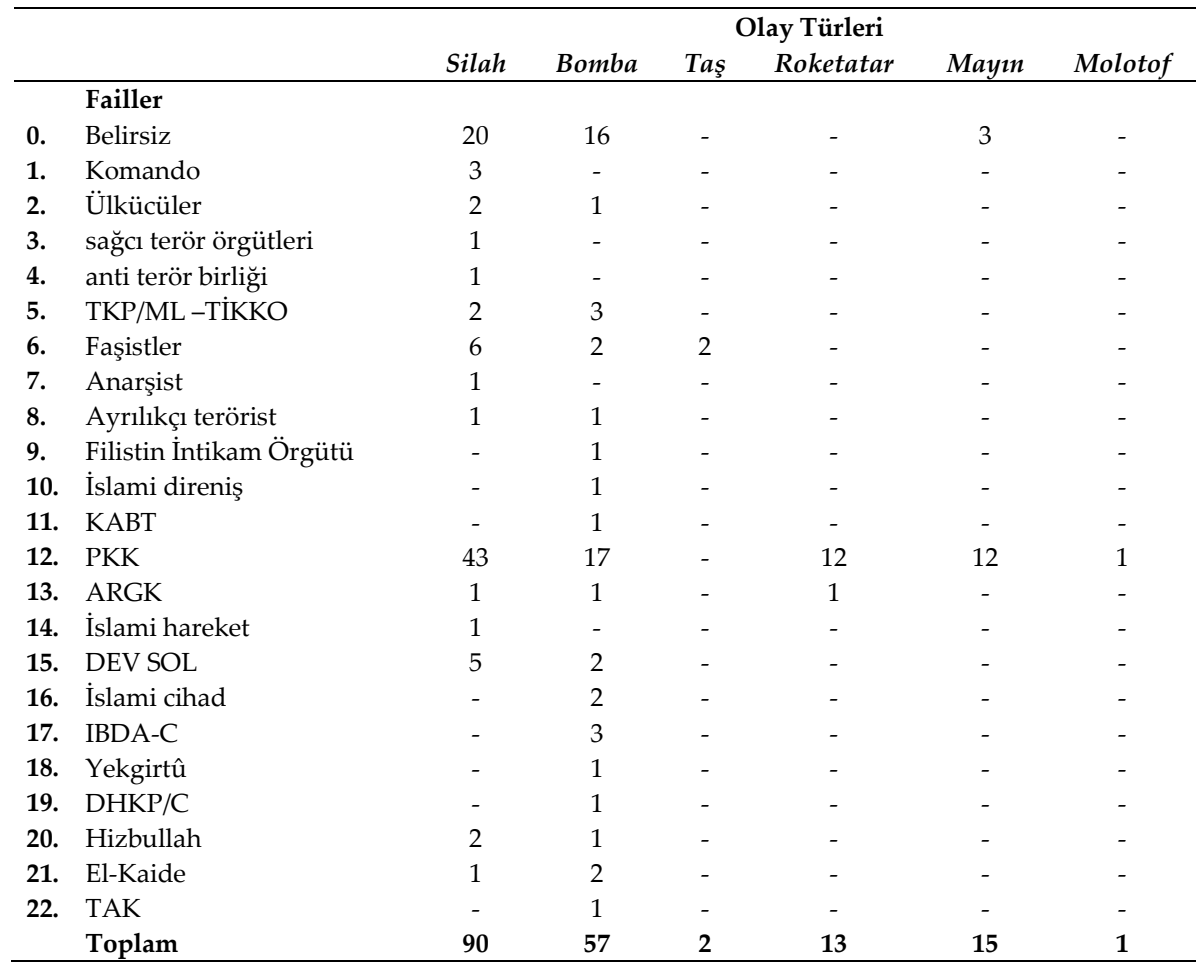

Tablo 11'e göre terör saldırılarında silah, bomba, taş, roketatar, mayın ve molotof kullanılmıştır. Silah; (gazetenin fail isimlendirmelerine göre) komandolar, Ülkücüler, sağc1 terör örgütleri, anti terör birliği, TKP/ML - TIKKKO, Faşistler, anarşistler, ayrılıkçı teröristler, PKK, ARGK, İslami Hareket, DEVSOL, Hizbullah ve El-Kaide tarafından terör saldırılarında kullanılmıştır. Bombalı eylemler; ülkücüler, TKP/ML -TİKKO, Faşistler, ayrılıkçı teröristler, Filistin İntikam Örgütü, İslami direniş, KABT, PKK, ARGK, DEV-SOL, İslami cihad, IBDA-C, Yekgirtû, DHKP/C, Hizbullah, El-Kaide ve TAK tarafından geçekleştirilmiştir. Roketatarlı saldırılar; PKK ve ARGK tarafından, mayın saldırıları ise PKK tarafından gerçekleştirilmiştir. Molotof kullanan sadece PKK olurken, taş kullananlar sadece faşistler olmuştur.

Tablo 10 ve Tablo 11; birlikte dikkate alındığında görülmektedir ki; PKK, 46 terör saldırısıyla askeri, 19 terör saldırısıyla sivilleri, 6 saldırıyla da polisleri 
hedef almıştır. \%50'den fazla saldırının türü silahlı saldırı şeklindedir. Saldırıların \%20'si bomba kullanarak, \%14,1'i roketatar, \%14,1'i mayın ve 1 tanesi de Molotof kullanarak gerçekleştirilmiştir.

İkinci olarak DEV-SOL dikkat çekmektedir. DEV-SOL'un ilk saldırısı 29 Aralık 1990 tarihinde gerçekleşmiş ve toplam 7 saldırının faili olmuştur. Saldırıların 5 tanesi manşetten verilmiş, diğer 2'si ise sayfa eteğinde yer almıştır. Saldırılarında; polisleri, askerleri, kamu görevlilerini ve sivilleri hedef almışlardır. 5 saldırıda silah, 2 saldırıda bomba kullanmışlar ve son saldırılarını 30 Temmuz 1992 tarihinde gerçekleştirmişlerdir.

"Faşistler" adı verilen saldırganların; 7 saldırıyla haber olmuş ve ilk saldırıların 30 Mayıs 1980 tarihimde gerçekleştirmişlerdir. 5 saldırı haberi manşetten verilirken, 2 tanesi sayfanın diğer kısımlarında yer almıştır. Saldırılarında; sivilleri, kamu görevlilerini, askerleri, milletvekillerini ve gayrimüslimleri hedef almışlardır. 6 saldııda silah, diğer saldırılarda ise bomba ve taş kullanmışlardır. Son saldırıları 7 Eylül 1986 tarihinde gerçekleşmiştir.

TKP/ML -TIKKKO; 5 saldırı ile gazetede yer almış ve ilk saldırı tarihi 22 Mayıs 1980'dir. 2 saldırı haberi manşetten verilirken, diğerleri sayfanın başka yerlerinden verilmiştir. Saldırılarında sivil, polis, öğretmen/öğrenci ve kamu görevlisini hedef alan örgüt, 2 defa silah, 3 defa bomba kullanmıştır ve son saldırısı nispeten daha yakın bir tarihte 14 Mayıs 2006'da olmuştur.

Ülkücüler adıyla anılan terörist grup, ilk saldırısını 7 Haziran 1978 tarihinde olmak üzere, toplam 3 saldırı gerçekleştirmiştir. Saldırı haberleri hep manşet dışı verilmiştir. Öğretmen, öğrenci ve sivil vatandaşları hedef alan saldırılarda, silah ve bomba kullanılmıştır. Son saldırıları; 2 Ocak 1980 tarihinde olmuştur.

Komandolar adı verilen saldırganlar; 22 Haziran 1977 tarihinde ilk sald1rılarını gerçekleştirmiştir. Saldırı haberlerinin hepsi manşet dışı yerden verilmiştir. Sivilleri ve polisleri hedef alan komandolar; toplam 3 saldırıda sadece silah kullanılmıştır. Son saldırıları 23 Mayıs 1978 senesinde olmuştur.

Hizbullah terör örgütü; ilk saldırısını 17 Şubat 2000 senesinde gerçekleştirmiştir. 1 saldırı haberi manşetten verilirken, diğer 2 haber manşet dışı yerden verilmiştir. Sivilleri ve kamu görevlilerini hedef alan terör örgütü, sald1rılarında silah ve bomba kullanmışlardır. 2010 yılına kadar olan son saldırıları 13 Eylül 2006'da gerçekleşmiştir.

IBDA-C terör örgütü 31 Aralık 1994 tarihinde ilk saldırısını gerçekleştirmiştir. Haber olarak 1 defa manşette yer almışlardır. Toplam 3 saldırının faili 
olan örgüt, her seferinde bomba kullanmışlar ve hedeflerinde hep siviller yer almıştır. Son saldırıları 8 Ekim 1996'da olmuştur.

El-Kaide terör örgütü; ilk saldırısını 16 Kasım 2003 tarihinde gerçekleştirmiştir ve bu habere manşetten yer verilmiştir. Toplam 3 saldırı haberi ile gazetede yer alan örgüt; gayrimüslimleri, sivilleri ve konsolosluk çalışanlarını hedef almıştır. Hepsinde bomba ve silah kullanan örgüt, son eylemini 10 Temmuz 2008'de gerçekleştirmiştir.

İslami Cihad adıyla anılan terör grubu; 2 terör olayının faili olarak gazetenin manşet dışı sayfasında yer almıştır. İlk saldırı haberi 27 Mart 1991 tarihinde olmuştur. Sivilleri ve askerleri hedef alan grup; sadece bomba kullanmıştır. 9 Mart 1992 tarihinde son saldırısını gerçekleştirmiştir.

Ayrılıkçı teröristler olarak adlandırılan terör grubu; 1984 senesinde 2 saldırı gerçekleştirmiş ve ikisinde de askeri hedef almışlardır. Her iki saldıı haberi de manşet dışı verilmiştir ve hem bomba hem de silah kullanılmıştır. Son saldırı 12 Ekim 1984'te gerçekleşmiştir.

"Sağcı terör örgütü" olarak adlandırılan örgüt tek saldırısını, 12 Temmuz 1978 tarihinde, bir sivile karşı silah kullanarak gerçekleştirmiştir. Habere, sayfanın manşet dışı kısmında yer verilmiştir.

"Anti terör birliği" olarak adlandırılan örgüt tek saldırısını, 8 Aralık 1979 tarihinde, bir sivile karşı silah kullanarak gerçekleştirmiştir. Haber manşetten verilmiştir.

"Anarşistler" olarak adlandırılan örgüt tek saldırısını 27 Temmuz 1980 tarihinde; polisi, öğrenci ve işçileri hedef alarak gerçekleştirmiştir. Habere, sayfanın manşet dışı kısmında yer verilmiştir. Saldırıda silah kullanılmıştır.

İslami direniş Örgütü tek saldırısını 7 Eylül 1986' da gayrimüslimleri hedef alan bir bombalı saldırı şeklinde gerçekleştirmiş ve haber manşetten verilmiştir.

ARGK tek saldırısın 22 Haziran 1987'de sivillere karşı gerçekleştirmiş ve saldırıda aynı anda silah, bomba ve roketatar kullanmıştır. Sivilleri hedef alan örgütün eylemlerine manşetten yer verilmiştir.

"İslami hareket" olarak adlandırılan örgüt tek saldırısını 1 Şubat 1990 senesinde gerçekleştirmiştir. Bir öğretmeni hedef alan ve silah ile gerçekleştirilen bu saldırı manşetten verilmiştir.

Yekgirtû, tek saldırısını 29 Ağustos 1995 tarihinde sivilleri hedef alan bir bombalı saldırı şeklinde gerçekleştirmiş ve sayfanın manşet dışı kısmında yer almıştır. 
DHKP/C tek saldırısını 28 Şubat 1998' de; askerlere karşı bir bombalı saldırı şeklinde gerçekleştirmiştir. Saldırı haberi sayfanın manşet dışı kısmında yer almıştır.

TAK tek saldırısını 10 Şubat 2006 tarihinde gerçekleştirmiştir. Saldırının hedefinde polisler vardır ve bomba kullanılmıştır. Saldırı haberi sayfanın manşet dışı kısmında yer almıştır. Bu sonuçlar; örgütlerin birden fazla saldırısı olmuş olsa da, gazetenin ilk sayfasına yansımamış olabileceğini düşündürmektedir.

32 saldırının faili belirsiz olarak nitelendirilmiştir. 1980 ve 2009 seneleri arasındaki faili ile ilgili bilgi verilmeyen / faili bilinmeyen saldırılarda; 19 defa siviller, 13 defa askerler, 7 defa polisler, 2 defa kamu görevlileri, 1 defa da siyasetçi hedef alınmıştır. 20 silahlı saldırı, 16 bombalı saldırı ve 3 mayın saldırısı gerçekleşmiştir.

\section{Tartışma}

Terörist saldırıları gerçekleştiren kişi ve/veya gruplar; yaptıkları eylem sonrası bir şekilde medyada yer alacakların bilirler. Bu sebeple terör faaliyetlerini mevcut medyanın özelliklerine göre kurgulamakta bir beis görmezler (Schmid, 1982). Terörizmde amacın, bir kişiyi öldürmek değil, bu yolla geniş kitleler üzerinde etki sağlamak olduğu ve bu sebepten terörün gerçekte bir iletişim hareketi olduğu ve yazılı basının bu hususta önemli bir role sahip olduğu kabul edilmektedir (Ergil, 1991, Fowler, 1991, Mc Quail 2013, Mortensen, 2015).

Küresel Terörizm Veritabanı (KTV)'na göre, 1970-2009 yılları arasında, yarıdan fazlası (\%62) 2001 yılı öncesine ait olmak üzere, Türkiye' de 2260 terörist eylem gerçekleşmiştir (Global Terrorism Database, 2019). Cumhuriyet Gazetesinin yalnızca basılı nüshasının, terör saldırısını izleyen güne ait ilk (birinci) sayfaları, 01.01.1930 - 01.01.2010 tarih aralığında incelenmiş ve "terör eylemi" veya "terör saldırısı" olarak nitelendirilebilecek her türlü olaya ait haber analiz edilmiştir. Belirtilen tarih aralığında; ilk sayfadan verilen ilk terör olayı 1977 senesinde gerçekleşmiştir ve o tarihten 01.01.2010 tarihine dek toplam 156 terör olayı haber yapılmıştır. Gerçekleşen 2260 terör eyleminin sadece \%6,90'1 (N=156) Cumhuriyet Gazetesi'nin ilk sayfasında yer alması düşük bir oran olarak gözükmektedir. Bu sonucun, haberlerin içeriğinde terör, "saldırı ve patlama kelimelerinin hiçbirinin bulunmaması durumunda, olay bir terör saldırısı 
olsa dahi araştırmamızın kapsamı dışında bırakılması" olarak düşünülebilir. Bununla birlikte; gazetenin sadece basılı versiyonlarındaki terör saldırısını izleyen güne ait ilk (birinci) sayfalarındaki saldırı haberleri araştırmamıza dâhil edildiği için; gazetenin ilk sayfa dışındaki bir yerinde yer alan haberler terör saldırısı olsa da dâhil edilmemiştir.

156 haberde, toplam 58 görsel kullanılmış ve bu görsellerin çoğunluğu olay yeri fotoğrafları ve olayın meydana geldiği bölgenin krokisi / haritası şeklindedir. Görsel kullanılan gazete haberlerinin; görsel kullanılmayan haberlerine göre, okuyucuda daha fazla duygusal bağ ve merak uyandırdığı bilinmektedir (Çekçeki, 2010, Cho ve diğerleri, 2003). Kullanılan görsellerin içerikleri de son derecede önem arz etmektedir. Medyada yer alan tüm haberlerdeki görsel içerikler; okuyucuda ve/veya izleyicide olaya dikkat çeken bir etki yaratabileceği gibi, hem olumsuz bir etki yaratabileceği hem de terör örgütlerinin ve/veya gruplarının amaçlarına hizmet edici bir tesiri olabileceği unutulmamalıdır (Çekçeki, 2010, Kazan, 2016).

Haberlerin başlıklarının büyük çoğunluğu $(\% 66,02)$ "doğrudan eylemi açıklayıcı" niteliktedir ("PKK tren bastı", "otobüse terör saldırısı" ve "teröristler asker aracı taradı" gibi...). Haberlerinin büyük çoğunluğunda doğrudan eylemi açıklayıcı bir söylem kullanılması; okuyucuda hüzün, üzüntü, neşe, mutluluk, rahatlama gibi duyguları uyandırmayı amaçlayan bir yaklaşım olan "duygusal yaklaşım" dan ziyade; haberlerde kullanılan başlıkların söylemlerinde, nesnel bir dilin tercih edildiği şeklinde yorumlanabilmektedir (Picard 1993). Öznel bir anlatım ile verilen "terör kol geziyor", "İstanbul'da terör gecesi", "Terör durmak bilmiyor" gibi infial yaratan söylemler ise, saldırı boyutunun ve/veya zayiatın büyük oluşu ile ilişkilendirilip, daha öznel bir yaklaşım sergilemesinin temel nedeni olarak gösterilebilmektedir.

Türkiye'nin; 1970'li senelerin sonlarından beri; dini motifli, etnik ayr1lıkçı/milliyetçi temelli, ideolojik sol kökenli veya ideolojik sağ kökenli olmak üzere çok çeşitli terörist faaliyetler ile karşılaştı̆̆ı görülmektedir (Global Terrorism Database, 2019). Belirtilen dönemdeki terör olaylarının faili olarak toplam 22 terör örgütü ve/veya grubu tespit edilmiştir. Yapılan analizler sonucunda; 80 senelik dönemde; en fazla faaliyet gösteren terör grupların ve/veya örgütlerin İslamcı silahlı terör örgütleri (Filistin İntikam Örgütü, İslami Direniş Örgütü, KABT, İslami Hareket, İslam Cihad, IBDA-C, Hizbullah ve ElKaide) olduğu saptanmıştır. Bu örgütler 1977'den 2009'a kadar her dönemde 
aktiftir. Sağ görüşlü terör grupları olarak adlandırılan Komandolar, ülkücüler, sağcl terör örgütleri ve faşistler ise, 1970'lerden 1980 senesine kadar faaliyet göstermiştir. Sol tandanslı gruplar olarak nitelendirilen Anti-Terör Birliği, Anarşistler, TKP/ML - TíKKO, DEV-SOL ve DHKP/C'nin ise özellikle 1980 senesinde ve 90'lı yıllarda aktif olduğu görülmüştür. PKK, ARGK, Yekgirtû ve TAK gibi Kürt hareketine bağlı terörist grup ve/veya örgütlerin; 1986 senesinden 2009 senesine kadar faaliyetlerini aralıksız sürdürdügü görülmektedir.

Emniyet Genel Müdürlüğü'ne bağlı Terörle Mücadele Daire Başkanlığı tarafından 2007 senesinde yapılan bir araştırmaya göre; Türkiye'de "aktif" durumda olan 12 terör örgütü olduğu belirtilmiştir. Bu örgütlerin ise $\mathrm{DHKP} / \mathrm{C}$, TKP/ML, MKP (Maoist Komünist Partisi), Marksist Leninist Komünist Parti (MLKP), PKK, KONGRA-GEL (Kürdistan Halk Kongresi-KHK), Kürdistan Devrim Partisi (PŞK), Kürdistan Demokrat Partisi (PDK), Bakur, Hizbullah, Hilafet Devleti (HD), IBDA/C, Tevhid-Selam (Kudüs Ordusu) ve El Kaide Terör Örgütü (Türkiye Yapılanması) olduğu saptanmıştır (Türkiye'de 12 aktif terör örgütü var, 2007). Çalışmamızda yer alan terör örgütleri ile karşılaştırıldığında; MKP (Maoist Komünist Partisi), Marksist Leninist Komünist Parti (MLKP), Kürdistan Devrim Partisi (PŞK), Kürdistan Demokrat Partisi/Bakur (PDK/Bakur), Hilafet Devleti (HD) ve Tevhid-Selam (Kudüs Ordusu) isimli terör örgütlerin ve/veya gruplarının; belirtilen tarihler arasında (01.01.193001.10.2010) Cumhuriyet Gazetesi 1. Sayfasında yer alan herhangi bir terör saldırısının faili olmadıkları görülmektedir. Bu farkın; var olan herhangi bir oto sansür, olaydan hemen sonra gelmiş olan yayın yasağı, olayın haber değeri taşıyıp taşımaması, olayın haberinin başka bir sayfada verilmesi gibi sebeplerden dolayı gerçekleştiği düşünülmektedir.

Çalışmamız; 1930-2009 seneleri arasında Cumhuriyet Gazetesi'nin yazılı nüshalarının ilk sayfalarında yer alan terör olaylarını incelemek üzerine bir içerik analizi çalışmasıdır. Aynı dönem içerisindeki terör haberlerinin kurgusunun nasıl yapılandırıldığını incelemek için, yapılacak bir çalışmayla detaylı bir söylem analizine ihtiyaç olduğu düşünülmektedir. Bununla birlikte; daha geniş bir örneklem üzerinde, diğer ulusal gazeteleri de entegre ederek yap1lacak bir çalışma literatüre faydalı katkılar sağlayacaktır. 


\title{
EXTENDED ABSTRACT
}

\section{Terrorist Attacks in Newspaper Reports: Cumhuriyet Newspaper 1930-2009 Sample}

\author{
* \\ Ceren Özbaşaran Tan-Neylan Ziyalar-Faruk Aşıcıoğlu \\ İstanbul University Cerrahpaşa
}

The main purpose of the study is to perform content analysis to classify the news about the terrorist attacks that took place within the borders of the Republic of Turkey. Cumhuriyet Newspaper as a national newspaper has been designated as a source among the newspapers that have the duty to inform the public. The terorist attacks occured in the Republic of Turkey between 1930-2009 are examined and the comman points were determined and the common points of these terrorist attacks are examined. Perpetrators, victims, species, and places were determined and profiles were created accordingly. Then the profiles with these common points are encoded so that they are meaningful in themselves, and the categories are made as a result of codes. For statistical analysis of the findings, the IBM SPSS 21.00 (statistical package program for the Social Sciences) statistical program is used. Descriptive statistics such as percentage, frequency, mean and standard deviation were used when evaluating the data.

Only the first page (of the day after the terrorist attack of the printed version) of Cumhuriyet Newspaper, which has been determined as the source, has been included in the study. The oldest date available in the newspaper's electronic archive was January 1, 1930. For the 80-year period from the determined date to January 1, 2010, news of any incident that could be described as "terrorist act" or "terrorist attack" has been reached.

As a result of searches made with the previously determined search criteria; A total of 156 events that could be described as "terrorist attacks" were identified. While these events are reported; 43 of them are from the headline, the others are located elsewhere on the first page. 156 incidents have a total of 22 perpetrators. The perpetrators are entitled as Commandos, Idealists, Right-wing Terrorist Organizations, Anti-Terrorist Associations, TKP / ML - 
TİKKO, Fascists, Anarchists, Separatist Terrorists, Palestine Revenge Organization, Islamic Resistance Organization, KABT, PKK, ARGK, Islamic Movement, DEV-SOL, Islam Jihad appeared in the newspaper with the names of IBDA-C, Yekgirtû, DHKP / C, Hizbullah, Al-Qaeda and TAK. The first headline news appeared in the newspaper in 1979, and the first one out of headline news appeared in the newspaper in 1977. 22 terrorist organizations / terrorist groups determined to be operating were identified. In $61.08 \%$ of the news, no visual was used and differences in terms of discourse (such as direct explanatory action, brutality, indignation, targeting...) are determined.

In the headline news examined; it is seen that terrorist attacks are mostly targeted by civilians $(\mathrm{N}=28)$. Civilians were targeted in street, house, office, cafe / restaurant, bank, association / foundation and market malls, respectively. When the news of terrorism out of headlines is examined; it was determined that civilian citizens were targeted by terrorist attacks 61 times, soldiers were targeted 51 times and police forces were targeted 15 times.

Moreover; when the terrorist attacks' locations are analysed; it has been found that civilians are mostly targeted in the streets, in public transportation and in their homes; whereas the soldiers were targeted in the military vehicles. Weapons, bombs, stones, rocket launchers, mines and molotov are used in terrorist attacks. Guns are used by idealists, right-wing terrorist organizations, anti-terrorist units, TKP / ML -TIKKKO, fascists, anarchists, separatist terrorists, PKK, ARGK, Islamic Movement, DEV-SOL, Hezbullah and Al-Qaeda. Bomb are used by idealists, TKP / ML -TİKKO, Fascists, separatist terrorists, Palestinian Revenge Organization, Islamic resistance, KABT, PKK, ARGK, DEV-SOL, Islamic jihad, IBDA-C, Yekgirtû, DHKP / C, Hizbullah, AlQaeda and TAK. Rocket launcher attacks are performed by PKK and ARGK and mine attacks were carried out by PKK. The indviduals and / or groups carrying out terrorist attacks, know that they will be in the media in a way after their actions. In terrorism, the aim is not only to kill a person, but also to have an impact on the masses in this way.

According to the Global Terrorism Database (KTV), between 1970-2009, 2260 terrorist actions took place in Turkey, with more than half $(62 \%)$ of those have taken place before 2001 . Only $6.90 \%(\mathrm{~N}=156)$ of the 2260 terrorist acts that took place appears to be on the first page of Cumhuriyet Newspaper, which can be considered as a low rate. The reason of it might be the exclusion the words of attack and explosion, even if the incident is a terrorist attack. 
Our study is a content analysis study on examining the terrorist incidents in the first pages of the written copies of Cumhuriyet Newspaper between 19302009. It is thought that a detailed discourse analysis is needed along with a study to be conducted to examine how the fiction of the terrorist news in the same period is structured. However; a much more study on a larger sample, by integrating other national or international newspapers, will definaltely provide useful contributions to the terror or international security related literature.

\section{Kaynakça / References}

Akgün, B. (2006). Küresel terör: Mit mi? Gerçek mi?. Terörün Görüntüleri, Görüntülerin Terörü, Orhan Gökçe ve Uğur Demiray (ed.), Konya: Çizgi Kitabevi.

Alali O. A., (1994). Media coverage of terrorism: Methods of diffusion. Thousand Oaks, CA: Sage Publications.

Andress, D. (2008). 'La violence populaire durant la Révolution française: révolte, châtiment et escalade de la terreur d'État', in M. Biard (ed.), Les politiques de la Terreur (1793-1794) Rennes: Presses Universitaires de Rennes, 69-80.

Ayhan, H. (2015). Terör kavraml, güvenlik konseyi ve genel kurul özelinde Birleşmiş Milletler'in 2001 sonrası terör yaklaşımı. Güvenlik Stratejileri Dergisi, 21, 117-146.

Berelson, B. ve Lazarsfeld, P. F. (1948). The analysis of communication content, Chicago: University of Chicago Press.

Çağlar, I., Akdemir, K. H., ve Erol, M. (2018). Türk medyasında terörün ele alınışı. İstanbul: SETA Yayınları.

Çekçeki, Ö. (2010). Terör - Medya Etkileşimi: 27 Nisan 2009 İstanbul Bostancı Operasyonu. Polis Akademisi Güvenlik Bilimleri Enstitüsü Uluslararası Güvenlik Anabilim Dalı.

Cho, J., Boyle, M. P., Keum, H., Shevy, M. D., vd. (2003). Media, terrorism, and emotionality: Emotional differences in media content and public reactions to the September 11th terrorist attacks. Journal of Broadcasting \& Electronic Media, 47, 309-327.

Dedeoğlu, B. (2003). Terörizm üzerine karşılaştırmalar: Bermuda şeytanı. İstanbul: Boyut Kitapları, 439-474.

Eisenstein, E.L., (1991). La Révolution de l'imprimé dans l'Europe des premiers temps modernes, La Découverte, Paris.

Ergil, D., (1991). Terörizmin mantı̆̆ı ve hedefi. A.Ü. S.B.F. Dergisi, 46(1-2), A.Ü. Basımevi. 
Fine J. (2010). Political and philological origins of the term 'terrorism' from the ancient near east to our times. Middle Eastern Studies, 46(2), 271-288.

Fowler, R., (1991). Language in the news discourse and ideology in the press. Routledge, London.

Gabot T. (1987). La couvertur e du crime par la presse : un portrait fidèle ou déformé, Criminologie, 20(1), 79-98.

Geray Haluk (2014). Toplumsal araştırmalarda nicel ve nitel yöntemlere giriş. Kocaeli: Umuttepe Yayınları.

Gerbner, G. (1993). Violence et terreur dans les médias. Éditions UNESCO, n¹02. (n.d.). Global Terrorism Database., 06.09.2019 tarihinde https://www.start.umd.edu/gtd/search/Results.aspx?chart=attack\&search=turkey adresinden erişilmiştir.

Gueniffey, P. (2013). Chapitre 5 - Violence et Terreur dans la Révolution française. Dans. , P. Gueniffey, Histoires de la Révolution et de l'Empire Paris: Éditions Perrin, 157-197.

Hoffman, B. (1998). Inside terrorism. New York: Columbia University Press,.

Hoffman, B. (2003). Al Qaeda, trends in terrorism, and future potentialities:An assessment," Studies in Conflict and Terrorism, 26, 6-18.

Kazan, H. (2016). Terör-medya ilişkisi ve medyada terör haberciliği. Güvenlik Stratejileri Dergisi, 12(24), 109-146.

Krippendorff, K. (2004). Content analysis: An introdustion to its methodology, Sage Publications. USA. 2.

Krippendorff, K. (2013) Content analysis: An introduction to its methodology. (3rd ed). California, CA: Sage Publications.

Kutlu, R. (2010). Uluslararası terörizm ve 11 eylül sonrasında Türkiye'nin terörizmle mücadelesi. Yayınlanmamış Yüksek Lisans Tezi, Karadeniz Teknik Üniversitesi, Sosyal Bilimler Enstitüsü, Trabzon.

Laqueur, W. (1987). The Age of Terrorism, Boston: Little Brown and Company.

Mc Quail, D. (2013). Kitle iletişim araçlarının etkileri. Der. R. Kaya, K. Alemdar, Kitle Illetişiminde Temel Yaklaşımlar, Ankara.

Mortensen, M. (2015). Conflictual media events, eyewitness images, and the Boston marathon bombing (2013). Journalism Practice, 9(4), 536-551.

Picard, R. G. (1993). Media portrayals of terrorism: Functions and meaning of news coverage, Ames: Iowa State University Press, 158.

Pooley, J. (2008). The new history of mass communication research. Chapter Two. İçinde The History of Media and Communication Research: Contested Memories, (Ed) D. Park, and J. Pooley, New York: Peter Lang, 43-69. 
Marion, P. (1993). Petite médiatique de la peur, in Protée. Théories et pratiques sémiotiques, Printemps.

Schmid, A., Graaf, J., (1982). Violence as communication insurgent terrorism and the western news media. Sage Publications InCilt, London.

Şeker, M. (2009). Terör ve haber söylemi. İstanbul: Literatürk.

Terörle Mücadele Kanunu, (2014) http://www.mevzuat.gov.tr/MevzuatMetin/1.5.3713-20140211.pdf

Türkiye Barolar Birliği Proje Grubu (2006). Türkiye ve terörizm: Rapor, Birinci Baskl, Ankara: Türkiye Barolar Birliği Yayınları, 107. http://tbbyayinlari.barobirlik.org.tr/ViewBooks.aspx?t=v\&YID=31

Türkiye'de 12 aktif terör örgütü var, (n.d) CNN Türk. https://www.cnnturk.com/2007/turkiye/12/24/turkiyede.12.aktif.teror.orgutu.var/413969.0/index.html adresinden erişilmiştir.

Wilkinson, P. (1997). The media and terrorism, terrorism and political violence, 9, Summer, London.

\section{Kaynakça Bilgisi / Citation Information}

Özbaşaran-Tan, C., Ziyalar, N. ve Aşıcıoğlu, F. (2020). Gazete haberlerinde terör saldırıları: Cumhuriyet gazetesi 1930-2009 örneklemi. OPUS-Uluslararası Toplum Araştırmaları Dergisi, 15(26), 4454-4478. DOI: 10.26466/opus.639941 